\title{
Replenishment and rationalization of seed collections of pumpkin, vegetable marrow and summer squash for ex situ conservation and use for breeding in Armenia
}

\author{
Alvina Avagyan *, Gayane Sargsyan, Raya Balayan and Laura Tadevosyan \\ Scientific Center of Vegetable and Industrial Crops of the Ministry of Economy of the Republic of Armenia, v. Darakert, \\ Ararat Marz, Republic of Armenia
}

\begin{abstract}
The conservation and sustainable use of crop genetic resources are crucial for food security and economic development, and diverse genetic resources are a critical input in the agricultural production process. To conserve the gene pool of vegetable crops of Armenia, the Scientific Centre of Vegetable and Industrial Crops of the Ministry of Economy of the Republic of Armenia carried out activities to upgrade storage facilities and optimize the existing seed collections. Newly created long-term and medium-term seed collections of pumpkin, vegetable marrow and summer squash reliably conserve genetic resources of these crops and create a base for undertaking genetic enhancement and base-broadening efforts. A database and application of barcodes and QR-code labels facilitate the search of required accessions, making the stored genetic materials more accessible for users and promoting their wider use in breeding.
\end{abstract}

Keywords: Cucurbitaceae, base collection, active collection, breeding

Citation: Avagyan, A., Sargsyan, G., Balayan, R., Tadevosyan, L. (2020). Replenishment and rationalization of seed collections of pumpkin, vegetable marrow and summer squash for ex situ conservation and use for breeding in Armenia. Genetic Resources 1 (1), 49-52. doi: 10.46265/genresj.2020.1.49-52.

(C) Copyright 2020 the Authors.

This is an open access article distributed under the terms of the Creative Commons Attribution License (CC BY 4.0), which permits unrestricted use, distribution, and reproduction in any medium, provided the original author and source are

credited.

\section{Introduction}

Vegetable production is one of the leading sectors in Armenian agriculture. Variation in agro-ecological conditions, climate and altitude in Armenia, as well as longtime traditions in multipurpose use of vegetables have led to a large diversity of vegetables grown by farmers. Among vegetables species of the Cucurbitaceae family, the following are of specific interest due to their palatability, nutritional value and dietary qualities: (1) pumpkin (Cucurbita maxima Duchesne, Cucurbita maxima var. turbaniformis (M.Roem.) L.H.Bailey, Cucurbita moschata Duchesne, Cucurbita pepo L.); (2) vegetable marrow (Cucurbita pepo L. subsp. pepo var. pepo L.); and (3) summer squash (Cucurbita pepo L. subsp. ovifera

${ }^{*}$ Corresponding author: Alvina Avagyan

(alvinaav@hotmail.com)
(L.) D.S.Decker). Dietary benefits of pumpkin and vegetable marrow are associated with a high content of vitamins C, B1, B2, B6, PP, E and carotenoids ( $\alpha$ - and $\beta$-carotene, lutein and zeaxanthin), a favorable ratio of potassium and sodium, and low calorie content. These crops are given a great importance in the production of baby food (Piskunova and Muteva, 2016). Summer squash is an excellent source of manganese, copper, folate, magnesium, potassium, and fiber, whereas vitamins $\mathrm{C}$ and $\mathrm{A}$ act as antioxidants, which may help to protect against hardening of blood vessels (Hashash et al, 2017). The nutritional value of pumpkin, vegetable marrow and summer squash makes these crops attractive both for large farms providing vegetables for canneries and for small landholders producing these crops in response to market demand. Moreover, ongoing state programmes on subsidizing agriculture and providing preferential loans and investments that are being put into the modernization of Armenia's greenhouse sector 
create an enabling environment for the introduction and cultivation of different vegetables, both in open fields and in greenhouses.

The Scientific Centre of Vegetable and Industrial Crops (SCVIC) has engaged in breeding and seed production of vegetable crops and provides growers with seeds of different varieties of pumpkin, vegetable marrow and summer squash that have been bred at the Centre and released in the country. So far, the numbers of locally bred varieties of the above-mentioned crops are not many: three varieties of vegetable marrow, four of pumpkin and one of summer squash. To meet grower and consumer demands in both production level and varietal diversity of cucurbitaceous vegetable crops there is a need for strengthening breeding programmes and undertaking genetic enhancement efforts. For this purpose, genetic resources of cucurbitaceous species are required as inputs into the continuing process of enhancement through selective breeding. To conserve and provide breeders with germplasm for further breeding programmes, the seed collection that over many years has been created and maintained at the SCVIC under room conditions was significantly improved by the purchase of freezers, the acquisition of new and regeneration of old accessions, and the rationalization of the existing ex situ collection (SackvilleHamilton et al, 2003) .

\section{Materials and methods}

Base and active collections were established both from newly introduced and regenerated germplasm as well as from accessions of working/breeding collections that were collected and maintained in paper bags over a period of about twenty years under room conditions without the possibility to control temperature and humidity. Accessions of foreign varieties have been received in the frameworks of collaboration projects with other countries with the purpose of testing under local conditions. Accessions of research material were received from the World Vegetable Center with the aim of multiplication and use in breeding programmes. Seeds of landraces were collected from local markets and farms. The process of acquisition of germplasm, seed drying, regeneration and storage of base and active seed collections was carried out in line with internationally accepted standards (FAO, 2014). To maintain the genetic integrity of original accessions during regeneration in open fields and avoid risk of outcrossing, plants were planted in blocks, not in rows, and $1,000 \mathrm{~m}$ isolation distance between different varieties was maintained. Seeds were collected from plants in the center of each block. In addition, samples with limited numbers of seeds were regenerated in individual polyethylene film greenhouses using handpollination.

Selected seed samples were dried to appropriate moisture content using a drying chamber. Before storing, initial seed viability tests were conducted. Dried seeds were placed in laminated aluminum foil bags of $11 \mu \mathrm{m}$ thickness and hermetically sealed. All seed packages were labeled with printed barcode and QR-code, which includes information on accession name, acquisition date, origin and biological status, reducing the possibility of errors and facilitating search of requested accessions. Accessions of the base collection are stored under long-term conditions at a temperature of $-18^{\circ} \mathrm{C}$. Material placed under mediumterm conditions (i.e. active collection) is stored under refrigeration at $5^{\circ} \mathrm{C}$.

Passport data for each accession are fully documented according to the FAO/Bioversity multi-crop passport descriptors (Alercia et al, 2015). The database for accession records is developed in Excel format compatible with EURISCO.

\section{Results and Discussion}

Purchasing the appropriate seed storage deep freezers and refrigerators, drying chamber, germination boxes and aluminum foil bags provided the possibility for establishing base and active seed collections, each with a specific target and coverage.

The active collection of pumpkin, vegetable marrow and summer squash was created to provide breeders, farmers, and researchers with seed material for study and use in breeding, research and educational programmes, as well as for seed material exchange. All Armenian varieties of pumpkin, vegetable marrow and summer squash released in the country since 1991 are included in the active collection regardless of their present cultivation area and market demand. The active collection includes 11 foreign varieties, which are in demand on the local market due to their economically important traits, such as early maturing and high productivity. Research material that, based on preliminary studies, has potential interest for breeders is also included in the active collection.

The base collection serves as safety material for the active collection and mainly includes varieties bred in Armenia, traditional farmers' varieties, as well as the most valuable breeding/research material of both local and foreign origin. Accessions were incorporated into the base collection based on the following criteria defined by a Scientific Council of the SCVIC:

- Strategic importance of a locally bred variety for the country's food production and sustainable agriculture. Widely cultivated varieties contributing to a country's food security are included in the base collection.

- Prevalence of local farmers' variety in the country. Landraces that are disappearing from markets and farmers' fields as a result of the spread of more productive modern varieties are placed under long-term storage conditions.

- Significance of a foreign variety for food security. Although the majority of the varieties of Cucurbitaceae cultivated in Armenia are of Armenian origin, in specific agro-climatic zones some foreign varieties ensure higher yields compared 


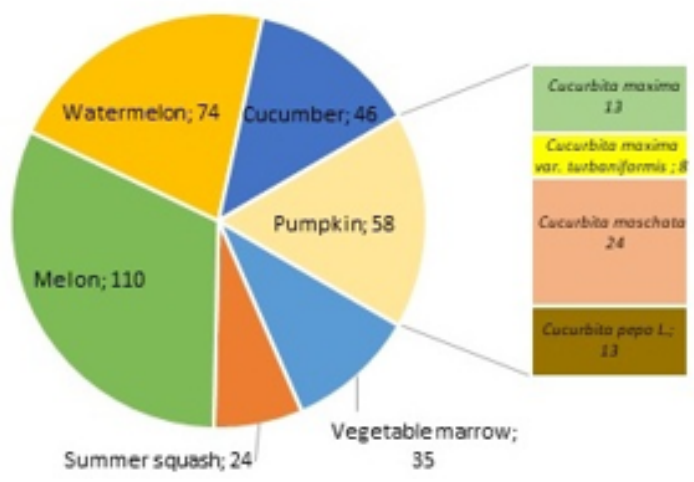

Figure 1. Structure of the base and active seed collections of the Cucurbitaceae family at the Scientific Centre of Vegetable and Industrial Crops, Armenia.

with local ones, and such varieties were added to the base collection.

- Value of less common variety in terms of a potential for a niche market. Varieties that are of specific interest for farms providing products for restaurants or high-end specialty stores were included in the base collection.

- High mean value for major breeding traits. Considering priority areas of breeding, research materials that could serve as a source of important traits, such as resistance to powdery mildew or early ripeness were incorporated into the base collection.

The SCVIC maintains a breeding collection of 88 accessions of pumpkin, vegetable marrow and summer squash, which is stored for a short period (from one to three years, depending on the species) under room conditions. Such collections are intended for breeding research conducted in the short term. Some accessions of the breeding collection have low initial germination or insufficient number of seeds, and must be regenerated, processed and stored in priority order.

The existing ex situ collections of pumpkin, vegetable marrow and summer squash were expanded by including obsolete varieties, landraces, research lines, samples obtained from partners in the framework of collaborative projects and cooperation with the World Vegetable Center. Accessions were requested according to the top priority areas of breeding of Cucurbitaceae species in the country, in particular high productivity, early ripeness, bushy growth habit and resistance to powdery mildew. At the same time, duplicate accessions and accessions with low seed variability were eliminated.

The enlarged seed collections of pumpkin, vegetable marrow and summer squash are not big compared with the collections of other species of the Cucurbitaceae family (Figure 1): they are new and contain valuable accessions of varieties and hybrids selected or bred in Armenia with viable seeds. In total, the collection (base and active) includes 117 accessions of six species and covers all available varieties, hybrids, breeding lines and landraces of Armenian origin.

The ratios of breeding varieties, research material and landraces vary depending on the crop. Thus, about
$72 \%$ of the seed collection of pumpkin are represented by modern varieties. Among accessions of vegetable marrow, the research material represented by breeder's lines, hybrids, and lines of individual selections from hybrid populations exceeds the number of accessions of modern breeding varieties (Figure 2). The summer squash collection is represented in equal quantity by varieties and research/breeding material.

In the base collections of pumpkin, vegetable marrow and summer squash, breeding varieties prevail, while most of the accessions of the active collections are represented by breeding and research material (Figure 2). Although there is a limited number of landraces of the gourd family existing in the country, the inventory indicated gaps in the collection in terms of farmers' varieties of pumpkin and vegetable marrow, which are being gradually displaced by commercially developed modern varieties. As for summer squash, this crop is a relatively new one in cultivation, so landraces do not exist.

Varieties of Armenian origin prevail over foreignintroduced varieties of pumpkin, vegetable marrow and summer squash in both collections. The number of accessions of introduced breeding/research material exceeds those of local origin, triggered by the need for diverse germplasm from outside Armenia in order to minimize genetic uniformity of new varieties.

\section{Conclusion}

As a result of establishing base and active collections of pumpkin, vegetable marrow and summer squash at the SCVIC the conservation of the genetic resources of these crops is ensured under conditions that meet internationally accepted standards. Due to the enlargement and rationalization of the ex situ collection, a resource base for genetic enhancement of these crops to produce substantial economic benefits was created. It can serve for breeding new varieties that meet requirements of local agricultural production, such as early maturity, high yield, resistance to pests and diseases, tolerance to abiotic stresses and other characteristics dictated by producers and consumers. The conserved genetic resources are available for users and can be provided upon request. As soon as the work on upgrading the collection of the remaining species of Cucurbitaceae, particularly bottle gourd (Lagenaria siceraria (Molina) Standl.) and loofah (Luffa aegyptiaca (L.) Roxb.) is finished, the passport data on all Cucurbitaceae accessions will be recorded in EURISCO to make the information on available accessions accessible for users at national and international levels.

The work on inventory of the collections, seeds viability tests and placing for long-term and midterm storage has started with crop species of the Cucurbitaceae family. This is the first step in upgrading the vegetable crops genetic resources collection and establishing properly managed seed collections. The future activities will be focused on further enlargement 


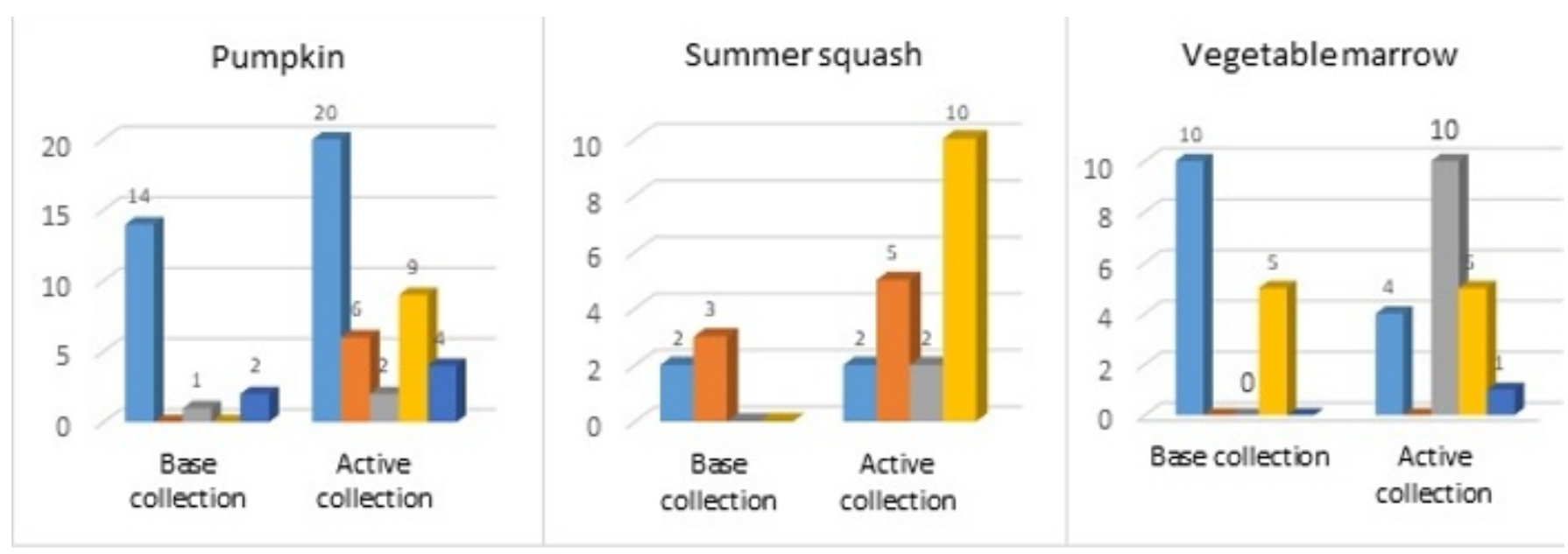

Figure 2. Numbers of accessions of local and foreign origin in base and active collections of pumpkin, summer squash and vegetable marrow at the Scientific Centre of Vegetable and Industrial Crops, Armenia.

of the collection through acquisition of genetic resources with genes linked to important agronomic traits such as disease resistance, stress tolerance and high nutritional value to expand the genetic spectrum of germplasm used in pre-breeding and breeding, and on efficient management of germplasm collections and relevant data through installation of an open-source program. The work of upgrading and rationalizing seed collections will continue for tomato, pepper and eggplant collections. It is planned to initiate the process of safety duplication of varieties of Armenian origin in the Svalbard Global Seed Vault upon finishing the upgrading and rationalization process for the entire vegetables collection.

\section{Acknowledgements}

Authors wish to thank the technical staff of the Scientific Centre for Vegetable and Industrial Crops (SCVIC) for assistance in seed drying, sorting and packaging. The SCVIC expresses its gratitude to Rijk Zwaan Breeding B.V. (The Netherlands) for providing laminated aluminum foil bags.

\section{Supplemental data}

Supplemental File 1: Abstract in Russian

\section{Author contributions}

AA established base and active collections, analyzed database information, wrote the manuscript; GS supervised the project on ex situ conservation, contributed to acquisition of germplasm; RB performed viability tests, selected seeds for ex situ conservation; TL collected seeds for ex situ conservation.

\section{Conflict of interest statement}

The Authors declare that no conflict of interest exists.

\section{References}

Alercia, A., Diulgherof, S., and Mackay, M. (2015). FAO/Bioversity Multi-Crop Passport Descriptors V.2.1 [MCPD V.2.1]. url: https://www.bioversityinternational.org/e-library/ publications/detail/faobioversity-multi-croppassport-descriptors-v21-mcpd-v21/.

FAO (2014). Genebank standards for orthodox seeds. In and others, In Genebank standards for plant genetic resources for food and agriculture rev. ed., FAO, Rome, Italy, 17-61.

Hashash, M. M., El-Sayed, M. M., Abdel-Hady, A. A., Hady, H. A., and Morsi, E. A. (2017). Nutritional potential, mineral composition and antioxidant activity squash (Cucurbita pepo L.) fruits grown in Egypt. European Journal of Biomedical and Pharmaceutical Sciences 4(03), 5-12.

Piskunova, T. M. and Muteva, Z. F. (2016). The VIR Collection - a source of initial breeding material for the perspective directions of breeding of a vegetable marrow and pumpkin . Vegetable crops of Russia 3, 1823. (in Russ.). url: https://doi.org/10.18619/20729146-2016-3-18-23.

Sackville-Hamilton, R., Engels, J. M. M., and van Hintum, T. (2003). Rationalization of genebank management. In A guide to effective management of germplasm collections, ed. Engels, J. and Visser, L., (Rome, Italy: IPGRI), volume 6 of IPGRI Handbooks for Genebanks, 80-92. 